Pacific Journal of Mathematics

PRODUCT INTEGRALS FOR AN ORDINARY DIFFERENTIAL 


\section{PRODUCT INTEGRALS FOR AN ORDINARY DIFFERENTIAL EQUATION IN A BANACH SPACE}

DAVID LOWELL LOVELADY

Let $Y$ be a Banach space with norm || , and let $R^{+}$be the interval $[0, \infty)$. Let $A$ be a function on $R^{+}$having the properties that if $t$ is in $R^{+}$then $A(t)$ is a function from $Y$ to $Y$ and that the function from $R^{+} \times Y$ to $Y$ described by $(t, x) \rightarrow A(t)[x]$ is continuous. Suppose there is a continuous real-valued function $\alpha$ on $R^{+}$such that if $t$ is in $R^{+}$then $A(t)-\alpha(t) I$ is dissipative. Now it is known that if $z$ is in $Y$, the differential equation $u^{\prime}(t)=A(t)[u(t)] ; u(0)=z$ has exactly one solution on $R^{+}$. It is shown in this paper that if $t$ is in $R^{+}$then $u(t)={ }_{0} \Pi^{t} \exp [(d s) A(s)][z]={ }_{0} \Pi^{t}[I-(d s) A(s)]^{-1}[z]$, where the exponentials are defined by the solutions of the associated family of autonomous equations.

The dissipitavity condition on $A$ is simply that if $(t, x, y)$ is in $R^{+} \times Y \times Y$ and $c$ is a positive number then

$$
|[I-c A(t)][x]-[I-c A(t)][y]| \geqq[1-c \alpha(t)]|x-y| \cdot
$$

The author and R. H. Martin, Jr. [5] have shown that if (1) holds, and $z$ is in $Y$, then there is exactly one continuously differentiable function $u$ from $R^{+}$to $Y$ such that

$$
u(0)=z
$$

and

$$
u^{\prime}(t)=A(t)[u(t)]
$$

whenever $t$ is in $(0, \infty)$. In the present article we shall show that $u$ can be expressed as a product integral in each of two forms:

$$
u(t)=\prod_{0}^{t} \exp [(d s) A(s)][z]
$$

and

$$
u(t)=\prod_{0}^{t}[I-(d s) A(s)]^{-1}[z] .
$$

Our work is related to results of J. V. Herod [2, §6] and G. F. Webb [7], [8]. Herod showed that representation (5) is valid if the mapping $(t, x) \rightarrow A(t)[x]$ is bounded on bounded subsets of $R^{+} \times Y$. Webb obtained in [7] a representation similar to (4) under a set of hypotheses different from, and independent of, those used here. In 
[8], Webb showed that (5) is valid if $A$ is independent of $t$. (Actually Webb in [8] restricted his attention to the case $\alpha=0$, but his proofs adapt easily to the general time-independent case.)

II. Product integrals. We shall assume throughout that $A$ and $\alpha$ are as in our introduction, and that (1) is true whenever $(t, x, y)$ is in $R^{+} \times Y \times Y$ and $c$ is a positive number. Now it follows from either of [5] and [6] that if $(t, x)$ is in $R^{+} \times Y$ then there is exactly one solution $v$ of the problem

$$
v^{\prime}(s)=A(t)[v(s)] ; v(0)=x .
$$

Furthermore, this problem generates an operator semigroup, which we shall denote $\left\{\exp [s A(t)]: s\right.$ is in $\left.R^{+}\right\}$, i.e., if $s$ is in $R^{+}$then $\exp [s A(t)]$ is a function from $Y$ to $Y$ such that if $x$ is in $Y$ then $\exp [s A(t)][x]=v(s)$, where $v$ solves $(6)$.

It is clear from (1) that there is no loss in assuming $\alpha$ to be $R^{+}$-valued, and we shall. It follows from [6] that if $(c, t)$ is in $R^{+} \times R^{+}$and $c \alpha(t)<1$ then $I-c A(t)$ is a bijection on $Y$, and

$$
\left|[I-c A(t)]^{-1}[x]-[I-c A(t)]^{-1}[y]\right| \leqq[1-c \alpha(t)]^{-1}|x-y|
$$

whenever $(x, y)$ is in $Y \times Y$. If $\left\{B_{1}, \cdots, B_{n}\right\}$ is a set of functions from $Y$ to $Y$, and $x$ is in $Y$, then $\Pi_{j=1}^{0} B_{j}[x]=x$ and $\prod_{j=1}^{k} B_{j}[x]=$ $B_{k}\left[\prod_{j=1}^{k-1} B_{j}[x]\right]$ whenever $k$ is an integer in $[1, n]$. If $(t, x, y)$ is in $R^{+} \times Y \times Y$ then the statement

$$
y=\prod_{0}^{t}[I-(d s) A(s)]^{-1}[x]
$$

means that if $\varepsilon$ is a positive number then there is a chain $\left\{r_{j}\right\}_{j=0}^{m}$ from 0 to $t$ such that if $\left\{s_{k}\right\}_{k=0}^{n}$ is a refinement of $\left\{r_{j}\right\}_{j=0}^{m}$, and $\left\{\widetilde{s}_{k}\right\}_{k=1}^{n}$ is a $[0, t]$-valued sequence such that if $k$ is an integer in $[1, n]$ then $\widetilde{s}_{k}$ is in $\left[s_{k-1}, s_{k}\right]$, then

$$
\left|y-\prod_{k=1}^{n}\left[I-\left(s_{k}-s_{k-1}\right) A\left(\widetilde{s}_{k}\right)\right]^{-1}[x]\right|<\varepsilon .
$$

The statement

$$
y=\prod_{0}^{t} \exp [(d s) A(s)][x]
$$

is defined analogously.

Theorem. Let $z$ be in $Y$, and let $u$ solve (2) and (3). Then each of (4) and (5) is true whenever $t$ is in $R^{+}$. 
Let $m_{-}$be that function from $Y \times Y$ to the real numbers given by

$$
m_{-}[x, y]=\lim _{\delta \rightarrow 0-}(1 / \delta)(|x+\delta y|-|x|) .
$$

Now (1) is equivalent to requiring that

$$
m_{-}[x-y, A(t)[x]-A(t)[y]] \leqq \alpha(t)|x-y|
$$

whenever $(t, x, y)$ is in $R^{+} \times Y \times Y$ (compare [1, p. 3]). Also, if $f$ is a function from a subset of $R^{+}$to $Y$, if $c$ is in the domain of $f$, if $f_{-}^{\prime}(c)$ (the left derivative of $f$ at $c$ ) exists, and if $P$ is given on the domain of $f$ by $P(t)=|f(t)|$, then $P_{-}^{\prime}(c)$ exists and $P_{-}^{\prime}(c)=$ $m_{-}\left[f(c), f_{-}^{\prime}(c)\right]$ (compare [1, p. 3]). If $(x, y, z)$ is in $Y \times Y \times Y$ then $m_{-}[x, y+z] \leqq m_{-}[x, y]+|z|$ (see [4, Lemma 6]). We are now prepared to prove our theorem.

Proof of the theorem. Let $b$ be a positive number, and let $\beta$ be a positive upper bound for the set $\{\alpha(t): t$ is in $[0, b]\}$. Let $\varepsilon$ be a positive number, and let $\delta$ be a positive number such that $(\delta / \beta)\left(e^{\beta b}-1\right)<\varepsilon$. Now $\{u(t): t$ is in $[0, b]\}$ is a compact subset of $Y$, so the function described by $(t, x) \rightarrow A(t)[x]$ is uniformly continuous on $[0, b] \times\{u(t): t$ is in $[0, b]\}$. In particular, there is a positive number $\eta$ such that if $(r, s, t)$ is in $[0, b] \times[0, b] \times[0, b]$ and $|r-s|<\eta$ then $\mid A(r)[u(t)]-$ $A(s)[u(t)] \mid<\delta$. Let $\left\{t_{k}\right\}_{k=0}^{n}$ be a chain from 0 to $b$ such that $t_{k}-t_{k-1}<\eta$ whenever $k$ is an integer in $[1, n]$, and let $\left\{\tilde{t}_{k}\right\}_{k=1}^{n}$ be a $[0, b]$-valued sequence such that if $k$ is an integer in $[1, n]$ then $\tilde{t}_{k}$ is in $\left[t_{k-1}, t_{k}\right]$. Let $v$ be that function from $[0, b]$ to $Y$ having the property that if $k$ is an integer in $[1, n]$ and $t$ is in $\left[t_{k-1}, t_{k}\right]$ then

$$
v(t)=\exp \left[\left(t-t_{k-1}\right) A\left(\tilde{t}_{k-1}\right)\right] \prod_{j=1}^{k-1} \exp \left[\left(t_{j}-t_{j-1}\right) A\left(\tilde{t}_{j}\right)\right][z] .
$$

Clearly now $v$ is continuous. Also, $v$ is left differentiable on $(0, b]$ : if $k$ is an integer in $[1, n]$ and $t$ is in $\left(t_{t-1}, t_{k}\right]$ then

$$
v_{-}^{\prime}(t)=A\left(\tilde{t}_{k-1}\right)[v(t)] \text {. }
$$

Let $P$ be given on $[0, b]$ by $P(t)=|v(t)-u(t)|$. Now $P(0)=0$. Suppose that $t$ is in $(0, b]$ and $k$ is an integer in $[1, n]$ and $t$ is in $\left(t_{b-1}, t_{k}\right]$. Now

$$
\begin{aligned}
P_{-}^{\prime}(t)= & m_{-}\left[v(t)-u(t), v_{-}^{\prime}(t)-u^{\prime}(t)\right] \\
= & m_{-}\left[v(t)-u(t), A\left(\tilde{t}_{k-1}\right)[v(t)]-A(t)[u(t)]\right] \\
= & m_{-}\left[v(t)-u(t), A\left(\widetilde{t}_{k-1}\right)[v(t)]-A\left(\tilde{t}_{k-1}\right)[u(t)]\right. \\
& +A\left(\tilde{t}_{k-1}\right)[u(t)]-A(t)[u(t)]
\end{aligned}
$$




$$
\begin{aligned}
\leqq & m_{-}\left[v(t)-u(t), A\left(\tilde{t}_{k-1}\right)[v(t)]-A\left(\tilde{t}_{k-1}\right)[u(t)]\right] \\
& +\left|A\left(\tilde{t}_{k-1}\right)[u(t)]-A(t)[u(t)]\right| \\
\leqq & \beta P(t)+\delta .
\end{aligned}
$$

Hence [3, Theorem 1.4.1, p. 15],

$$
P(t) \leqq \int_{0}^{t} \delta e^{\beta(t-s)} d s=(\delta / \beta)\left(e^{\beta t}-1\right)
$$

whenever $t$ is in $[0, b]$. In particular,

$$
\begin{aligned}
& \left|u(b)-\prod_{k=1}^{n} \exp \left[\left(t_{k}-t_{k-1}\right) A\left(\tilde{t}_{k}\right)\right][z]\right| \\
& \quad=|u(b)-v(b)| \\
& \quad=P(b) \\
& \quad \leqq(\delta / \beta)\left(e^{\beta b}-1\right)<\varepsilon .
\end{aligned}
$$

Thus we have proved that representation (4) is valid.

Now let $b$ and $\beta$ be as before. Let $c$ be a positive number such that $c \beta<1 / 2$. Now if $t$ is in $[0, b]$ and $r$ is in $[0, c]$ then

$$
\begin{aligned}
\mid[I & -r A(t)]^{-1}[x]-[I-r A(t)]^{-1}[y] \mid \\
& \leqq[1-r \beta]^{-1}|x-y| \\
& \leqq(1+2 r \beta)|x-y| \\
& \leqq e^{2 r \beta}|x-y|
\end{aligned}
$$

whenever $(x, y)$ is in $Y \times Y$.

Now let $K=\{u(t): t$ is in $[0, b]\}$, and recall that $K$ is compact. Let $\varepsilon$ be a positive number. By the aforementioned uniform continuity, there is a positive number $\eta_{1}$ such that if $(s, t, x, y)$ is in $[0, b] \times$ $[0, b] \times K \times K$ and $|s-t|<\eta_{1}$ and $|x-y|<\eta_{1}$ then $|A(s)[x]-A(t)[y]|<$ $(\varepsilon / b) e^{-2 \beta b}$. Let $\eta_{2}$ be a positive number such that if $(s, t)$ is in $[0, b] \times$ $[0, b]$ and $|s-t|<\eta_{2}$ then $|u(s)-u(t)|<\eta_{1}$. Let $\delta=\min \left\{\eta_{1}, \eta_{2}, c\right\}$. Suppose that $0 \leqq r \leqq s \leqq t \leqq b$ and $t-r<\delta$. Let $\left\{\xi_{k}\right\}_{k=0}^{n}$ be a chain from $r$ to $t$, and let $\left\{\tilde{\xi}_{k}\right\}_{k=1}^{n}$ be a $[r, t]$-valued sequence such that if $k$ is an integer in $[1, n]$ then $\tilde{\xi}_{k}$ is in $\left[\xi_{k-1}, \xi_{k}\right]$. Now

$$
\begin{aligned}
& \left|\sum_{k=1}^{n}\left(\xi_{k}-\xi_{k-1}\right) A\left(\tilde{\xi}_{k}\right)\left[u\left(\tilde{\xi}_{k}\right)\right]-(t-r) A(s)[u(t)]\right| \\
& \quad \leqq \sum_{k=1}^{n}\left(\xi_{k}-\xi_{k-1}\right)\left|A\left(\tilde{\xi}_{k}\right)\left[u\left(\tilde{\xi}_{k}\right)\right]-A(s)[u(t)]\right| \\
& \quad \leqq \sum_{k=1}^{n}\left(\xi_{k}-\xi_{k-1}\right)(\varepsilon / b) e^{-2 \beta b}=(t-r)(\varepsilon / b) e^{-2 \beta b} .
\end{aligned}
$$


It is now clear that

$$
\begin{aligned}
& \left|\int_{r}^{t} A(\xi)[u(\xi)] d \xi-(t-r) A(s)[u(t)]\right| \\
& \quad \leqq(t-r)(\varepsilon / b) e^{-2 \beta b} .
\end{aligned}
$$

Let $\left\{t_{k}\right\}_{k=0}^{n}$ be a chain from 0 to $b$, and suppose that $t_{k}-t_{k-1}<\delta$ whenever $k$ is an integer in $[1, n]$. Let $\left\{\tilde{t}_{k}\right\}_{k=1}^{n}$ be a $[0, b]$-valued sequence such that if $k$ is an integer in $[1, n]$ then $\tilde{t}_{k}$ is in $\left[t_{k-1}, t_{k}\right]$. Now

$$
\begin{aligned}
\mid \prod_{k=1}^{n} & {\left[I-\left(t_{k}-t_{k-1}\right) A\left(\tilde{t}_{k}\right)\right]^{-1}[z]-u(b) \mid } \\
\leqq & \sum_{k=1}^{n} \mid \prod_{j=k+1}^{n}\left[I-\left(t_{j}-t_{j-1}\right) A\left(\tilde{t}_{j}\right)\right]^{-1}\left[u\left(t_{k}\right)\right] \\
& \quad-\prod_{j=k}^{n}\left[I-\left(t_{j}-t_{j-1}\right) A\left(\tilde{t}_{j}\right)\right]^{-1}\left[u\left(t_{k-1}\right)\right] \mid \\
\leqq & \sum_{k=1}^{n} e^{2 \beta\left(b-t_{k}\right)}\left|u\left(t_{k}\right)-\left[I-\left(t_{k}-t_{k-1}\right) A\left(\tilde{t}_{k}\right)\right]^{-1}\left[u\left(t_{k-1}\right)\right]\right| \\
\leqq & e^{2 \beta b} \sum_{k=1}^{n}\left|\left[I-\left(t_{k}-t_{k-1}\right) A\left(\tilde{t}_{k}\right)\right]\left[u\left(t_{k}\right)\right]-u\left(t_{k-1}\right)\right| \\
= & e^{2 \beta b} \sum_{k=1}^{n}\left|u\left(t_{k}\right)-u\left(t_{k-1}\right)-\left(t_{k}-t_{k-1}\right) A\left(\tilde{t}_{k}\right)\left[u\left(t_{k}\right)\right]\right| \\
= & \left.e^{2 \beta b} \sum_{k=1}^{n}\right|_{t_{k-1}} \int^{t_{k}} u^{\prime}(\xi) d \xi-\left(t_{k}-t_{k-1}\right) A\left(\tilde{t}_{k}\right)\left[u\left(t_{k}\right)\right] \mid \\
= & \left.e^{2 \beta b} \sum_{k=1}^{n}\right|_{t_{k-1}} \int^{t_{k}} A(\xi)[u(\xi)] d \xi-\left(t_{k}-t_{k-1}\right) A\left(\tilde{t}_{k}\right)\left[u\left(t_{k}\right)\right] \mid \\
\leqq & e^{2 \beta b} \sum_{k=1}^{n}\left(t_{k}-t_{k-1}\right)(\varepsilon / b) e^{-2 \beta b}=\varepsilon .
\end{aligned}
$$

The proof of the theorem is complete.

\section{REFERENCES}

1. W. A. Coppe], Stability and Asymptotic Behavior of Differential Equations, D. C. Heath \& Co., Boston, 1965.

2. J. V. Herod, A pairing of a class of evolution systems with a class of generators, Trans. Amer. Math. Soc., 157 (1971), 247-260.

3. V. Lakshmikantham and S. Leela, Differential and Integral Inequalities, vol. 1, Academic Press, New York, 1969.

4. D. L. Lovelady, A functional differential equation in a Banach space, Funkcialaj Ekvacioj, 14 (1971), 111-122.

5. D. L. Lovelady and R. H. Martin, Jr., A global existence theorem for a nonautonomous differential equation in a Banach space, Proc. Amer. Math. Soc., 35 (1972), 445-449.

6. R. H. Martin, Jr., A global existence theorem for autonomous differential equations in a Banach space, Proc. Amer. Math. Soc., 26 (1970), 307-314.

7. G. F. Webb, Product integral representation of time dependent nonlinear evolution equations in a Banach space, Pacific J. Math., 32 (1970), 269-281. 
8. G. F. Webb, Nonlinear evolution equations and product integration in a Banach space, Trans. Amer. Math. Soc., 148 (1970), 273-282.

Received June 7, 1972.

Florida State UNIVERSity 


\section{PACIFIC JOURNAL OF MATHEMATICS}

\section{EDITORS}

RICHARD ARENS (Managing Editor)

University of California

Los Angeles, California 90024

R. A. Beaumont

University of Washington

Seattle, Washington 98105
J. DUGUNDJI*

Department of Mathematics

University of Southern California

Los Angeles, California 90007

D. Gilbarg and J. Milgram

Stanford University

Stanford, California 94305

\section{ASSOCIATE EDITORS}
E. F. BECKENBACH
B. H. NeumanN
F. WOLF
K. YosHIDA

\section{SUPPORTING INSTITUTIONS}

UNIVERSITY OF BRITISH COLUMBIA
CALIFORNIA INSTITUTE OF TECHNOLOGY
UNIVERSITY OF CALIFORNIA
MONTANA STATE UNIVERSITY
UNIVERSITY OF NEVADA
NEW MEXICO STATE UNIVERSITY
OREGON STATE UNIVERSITY
UNIVERSITY OF OREGON
OSAKA UNIVERSITY

UNIVERSITY OF BRITISH COLUMBIA

UNIVERSITY OF CALIFORNIA

MONTANA STATE UNIVERSITY

UNIVERSITY OF NEVADA

OREGON STATE UNIVERSITY

OSAKA UNIVERSITY
UNIVERSITY OF SOUTHERN CALIFORNIA

STANFORD UNIVERSITY

UNIVERSITY OF TOKYO

UNIVERSITY OF UTAH

WASHINGTON STATE UNIVERSITY

UNIVERSITY OF WASHINGTON

\section{AMERICAN MATHEMATICAL SOCIETY} NAVAL WEAPONS CENTER

* C. R. DePrima California Institute of Technology, Pasadena, CA 91109, will replace J. Dugundji until August 1974. 


\section{Pacific Journal of Mathematics}

\section{Vol. 48, No. $1 \quad$ March, 1973}

Jan Aarts and David John Lutzer, Pseudo-completeness and the product of Baire

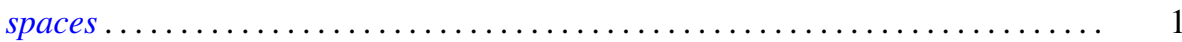

Gordon Owen Berg, Metric characterizations of Euclidean spaces ............ 11

Ajit Kaur Chilana, The space of bounded sequences with the mixed topology ..... . 29

Philip Throop Church and James Timourian, Differentiable open maps of

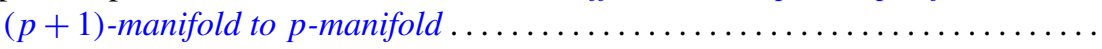

P. D. T. A. Elliott, On additive functions whose limiting distributions possess a finite

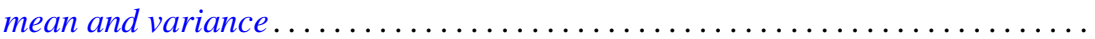

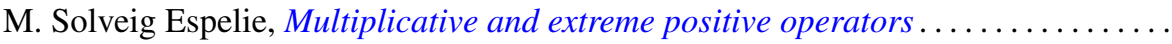

Jacques A. Ferland, Domains of negativity and application to generalized convexity

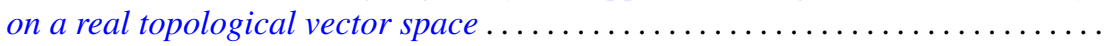

Michael Benton Freeman and Reese Harvey, A compact set that is locally holomorphically convex but not holomorphically convex ...............

Roe William Goodman, Positive-definite distributions and intertwining

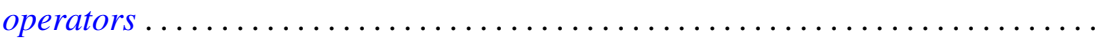

Elliot Charles Gootman, The type of some $C^{*}$ and $W^{*}$-algebras associated with

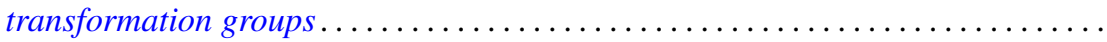

David Charles Haddad, Angular limits of locally finitely valent holomorphic

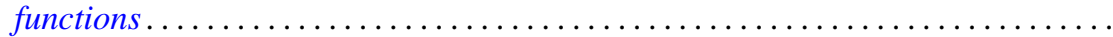

William Buhmann Johnson, On quasi-complements .

William M. Kantor, On 2-transitive collineation groups of finite projective spaces...

Joachim Lambek and Gerhard O. Michler, Completions and classical localizations of right Noetherian rings

Kenneth Lamar Lange, Borel sets of probability measures ......

David Lowell Lovelady, Product integrals for an ordinary differential equation in a Banach space

Jorge Martinez, A hom-functor for lattice-ordered groups .........

W. K. Mason, Weakly almost periodic homeomorphisms of the two sphere ....

Anthony G. Mucci, Limits for martingale-like sequences .......

Eugene Michael Norris, Relationally induced semigroups ...

Arthur E. Olson, A comparison of c-density and $k$-density ......

Donald Steven Passman, On the semisimplicity of group rings of linear groups.

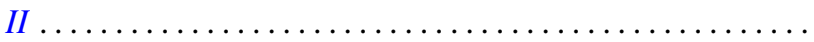

Charles Radin, Ergodicity in von Neumann algebras .

P. Rosenthal, On the singularities of the function generated by the Bergman operator of the second kind.

Arthur Argyle Sagle and J. R. Schumi, Multiplications on homogeneous spaces,

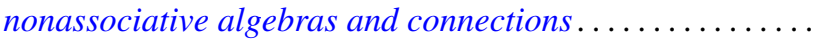

Leo Sario and Cecilia Wang, Existence of Dirichlet finite biharmonic functions on

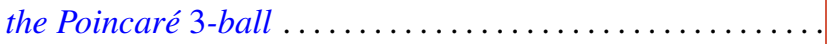

Ramachandran Subramanian, On a generalization of martingales due to Blake ..

Bui An Ton, On strongly nonlinear elliptic variational inequalities.

Seth Warner, A topological characterization of complete, discretely valued

fields. 